\title{
MECHANICAL PROPERTIES OF HYBRID FIBER REINFORCED LIGHWEIGHT CONCRETE AND ESTIMATION OF MECHANICAL PROPERTES BY NON-DESTRUCTIVE ULTRASOUND TEST
}

\author{
Hicran AÇIKEL* \\ "Necmettin Erbakan University, Faculty of Engineering and Architecture, Lecturer of Civil Engineering \\ Department, 42140, Konya, Turkey; \\ *Corresponding author Hicran Açıkel, e-mail: hacikel@erbakan.edu.tr;
}

Received August 2019; Accepted September 2019; Published October 2019;

DOI: https://doi.org/10.31407/ijees9409

\begin{abstract}
Concrete an essential building material of the century is a brittle material with low tensile strength in comparison with compressive strength. In order to improve tensile strength, various types of fibers are used not only increasing the ductility but also limiting the crack progression on concrete. In the last decade, hybrid fiber reinforced concrete has been popular which is limiting the propagation of micro cracks by fine fibers and controlling larger cracks by longer fibers. Light weight concrete differs from normal concrete by its lightness and the gaps enabled thermal insulation. In this paper, mechanical properties of hybrid fiber reinforced lightweight concrete (HFRC) were tested by conventional methods and non-destructive methods. Fresh and hardened properties of hybrid fiber reinforced lightweight concrete, produced by $6 \mathrm{~mm}$ long steel and $55 \mathrm{~mm}$ long polypropylene fibers, were studied both with destructive and non-destructive testing methods. Steel and polypropylene fibers in various rates were used both individually and together in the HFRC. Slump flow test and flow table tests were conducted in order to detect the workability of fresh concrete mixture. Further compressive strength, flexural strength and split tensile strength of hardened lightweight concrete was evaluated. Additionally, non-destructive ultrasound test was applied all specimens. It is figured out from both destructive and non-destructive tests that using polypropylene and steel fibers together in a proper rate contributes the mechanical properties of lightweight concrete.
\end{abstract}

Key words: Concrete, lightweight concrete, steel fiber, polypropylene fiber, hybrid fiber 